\title{
Predicted Single Nucleotide Polymorphism Frequency
}

National Cancer Institute

\section{Source}

National Cancer Institute. Predicted Single Nucleotide Polymorphism Frequency. NCI

Thesaurus. Code C135486.

The determination of the anticipated or extrapolated frequency of a single nucleotide polymorphism within a single interbreeding population. 